\title{
Modeling Method of City Based on Multidimensional Planning and Geo- graphic Information System
}

\author{
Liang Xiaoping ${ }^{1}, \mathrm{Hu}$ Xiangdong ${ }^{2}$ and Liu Xinyi ${ }^{3, *}$
}

\author{
${ }^{I}$ Xianyang Planning and design Institute , Xianyang , 71200, China, ${ }^{2}$ Protection and Renovation Office of Xi'an Quji- \\ ang Daming Palace Ruins Area, Xi'an, 710016, China; ${ }^{3}$ School of Architecture, Chang'an University, Xi'an, 710061, \\ China
}

\begin{abstract}
The development of computer hardware technology improves the mass data processing ability of the microcomputer. With the development of modern, the development of mathematical and computer graphics research and computer software technology, digital terrain, object technology has been developed, which provides the possibility for the traditional 3D city planning city planning. This paper introduces the combination of GIS and network technology, indepth study of the method of component based software development, this paper briefly introduces the significance and development of GIS system. Through the design of a city planning and traffic management system, clear the software development method of component based steps. This paper is mainly to study the city modeling method of 3D city planning based on the modeling method, at the same time is realized through the application development. In the process of application development, mainly two aspects: modeling method to establish the model of city model and attribute. Here we will city model is divided into two types of terrain and feature model, by using the model of overlapping method, the combination of the two models, the formation of city model.
\end{abstract}

Keywords: Component, component based software development, geographic information system

\section{INTRODUCTION}

Geographic Information System (GIS) is input, the storage of spatial data, search operations, analysis, modeling, display and output of the computer system, is a set of space science, remote sensing mapping model edge science, modern geography, information science, computer science, science, environmental science and management as a whole, and the rapid formation of a door the various disciplines and thawing all kinds of application object as one of the integrated high-tech [1]. It not only can manage data, text information and graphics, and spatial data is the research object, using the computer as a tool, the different sources, the combination of comprehensive analysis and query of attribute information of different types of data and related, the realization of computer information processing, and is a new effective integrated treatment system and analysis spatial data. At the same time, it is timely, rapid, accurate, and complete all kinds of data information query between graphics and attribute data, spatial query, analysis and calculation of thematic map compilation and other functions. And the utility model has the advantages of good compatibility and resource sharing [2-4].

With the development of computer graphics technology, $3 \mathrm{D}$ visualization, virtual reality technology and database management technology research in city planning and design in particular has played a huge role in 3D city modeling, but

*Address correspondence to this author at the School of Architecture, Chang'an University, Xi'an, 710061, China;

E-mail: 820120536@qq.com for 3D visualization, multi platform data sharing and VR data conversion, there are still many problems to be solved [5]. In addition, for City modeling with a large amount of data, multi standard by using virtual reality technology, special multi user interaction, making this technology popularization of practical, there is a long way to go [6].

Three and four dimensional processing of spatial data, is essentially three-dimensional continuous distribution. However, the main applications of GIS still remain in the treatment of the surface of the earth data, most of the GIS platform support point, line, surface of three kinds of spatial objects, can not support surface or body. In addition, the geographic information system described geographical objects often has the time attribute, adding the time dimension 3DGIS to form 4DGIS. With the passage of time, the characteristics of geographical objects will change, and this change is very great, but most of the current geographic information system, processing can well support geographic objects and composite event time dimension. Many GIS applications requirements are based on time characteristics.

\section{THE RAPID PROCESS OF CITY WITH COMPLEX PROBLEM}

\subsection{The Research Status of City Implement}

Starting from the division of application field, to analyze GIS application status at home and abroad to sum up there are two, one is to deal with the user using the data of GIS system; the two is based on GIS, using its function library two times to develop special software of geographic infor- 
mation system user. The main application mode has eight $[7,8]$ :

(1) The application of GIS in the geo spatial data management; such as the application of ARC/INFO in highway management; application of ARC/INFO in the management of municipal facilities in the;

(2) Application of evaluation and simulation and prediction of GIS in spatial analysis; such as American resources and Wisconsin cooperation established with the management of soil erosion is the main purpose of multipurpose special land GIS;

(3) Application of spatial query and spatial analysis function of GIS; there are many application examples, such as the city planning process, the city ambulance rescue train, the distribution location and route planning and control; how to arrange multiple police traffic routes, to ensure that in times of emergency, should have at least one the police car at the shortest time arrived at the scene at any place; in the aspects of environmental protection, to evaluate the soil and water loss leads to the destruction of land resources; in the evaluation of the current situation of the regional environmental quality in the process of environmental quality, the region as a whole, objectively, comprehensively evaluation.

\subsection{City Planning Information System}

Most of the GIS software in the management of city planning in the application at home and abroad, or is based on the file system, or is based on the relation database, although with a less powerful, but in the framework of city planning, spatial data and attribute data unified management and other technical problems still have not been completely resolved, it is difficult to form the city planning management application the actual operation of the system, are still unable to play the advantages of city planning and management information system. These problems are mainly embodied in the following aspects [9].

(1) Characteristics of the integration of planning management work of graphic data and attribute data of daily work is inseparable from the graph and table; each stage of planning and management process need different graphic references, tables and data; each stage to reference comparison between constantly; each stage but also produce a certain amount of charts and tables; between each different professional management to cross reference graph, table, different professional management

Statistics to different categories; the professional the phases to use drawing, editing, calculating, comparing a lot of tools etc. All of the graphics data and attribute data processing requirements with a stage, cross, continuation and computability, graph, text, table requirements throughout the entire process planning management. Therefore, the urban planning information system, if still in the relational database storage of attribute data and graphic data files, by way of storage, will make two kinds of data can not really achieve the unity, which greatly affect the efficiency of database retrieval query speed and even the whole system.

(2) The data organization problem of present data for the design of urban planning information system, is basically built in processing mode on the map on the. The traditional map data production focus on graphics, symbols, pay attention to the forms of effect, but not enough attention to information organization principle. Such as the feature class symbols as the key factor of the acquisition, in the real world should be connected in the graph but because things, drawing need to disconnect it and so on. When the need to establish information systems, the need to establish office assistant, management system, special system, the data will be exposed many problems.

(3) Planning and Management Office of the problems of urban planning management office is mainly for the construction project site submissions, construction land planning permits, construction planning permits, the so-called "book two cards", the application and approval process, tracking and supervision, flow control and cycle control, issue certificates and other business and data flow need of graphic and attribute data which runs through the features of the service usually also has a "long transaction".

\section{DATA ORGANIZATION AND MANAGEMENT OF CITY MODEL}

\subsection{The Static Model to the Dynamic Model}

Relative to the static model, dynamic model will be the time as a factor, the author discussed the change rules of the state of the system with time, change process research system. The city as a huge system, its dynamic evolution is more obvious and complex. The evolution of the theory of dissipative structure system is coordination theory and mutation theory joint research proposition, it involves a nonlinear dynamics of a sequence of profound theory. And the dynamic system is on the basis of system analysis, according to the system structure, the relationship and evolution characteristics, including the system state variables and control variables, the mathematical model, it appears in the differential equation or equations of the form. Set up a system of $\mathrm{N}$ state variables $\mathrm{x} 1, \mathrm{x} 2, \ldots, \mathrm{xn}$ control variable, then the mathematical expressions of the dynamic system can be written as:

$$
\left.\begin{array}{l}
\frac{d x_{1}}{d t}=f_{1}\left(x_{1}, x_{2}, \ldots, x_{n} ; \lambda_{1}, \lambda_{2}, \ldots, \lambda_{m}\right) \\
\frac{d x_{2}}{d t}=f_{2}\left(x_{1}, x_{2}, \ldots, x_{n} ; \lambda_{1}, \lambda_{2}, \ldots, \lambda_{m}\right) \\
\ldots . . \\
\frac{d x_{n}}{d t}=f_{n}\left(x_{1}, x_{2}, \ldots, x_{n} ; \lambda_{1}, \lambda_{2}, \ldots, \lambda_{m}\right)
\end{array}\right\}
$$

The $3 \mathrm{D}$ city modeling based on city planning is the basis for planning and design and analysis, the main contents include the establishment of 3D city modeling of city landscape model, the establishment of city feature attribute model database, then the object model editing, to reach the design requirements; the use of model attribute database, model of city planning and the planning of the query, index control provides support to achieve these functions, we will know how to build city model, to use what technology, below we on modeling methods and technologies to carry on the elaboration. 


\subsection{Modeling Based on Image and Geometry}

The boundary representation of the most commonly used means of law is a polygon surface description, which is composed of the corresponding vertex sets and attribute parameter determination, polygon data sheets available geometric form and attribute table said, geometric surface including the vertex coordinate and the direction of the surface parameters. Attribute table comprises a body surface of transparency of the parameters and the texture features, storage polygon geometry data can create three tables: vertex table, side table, as shown in Fig. (1) table polygon. Then the consistency and integrity checking of data.

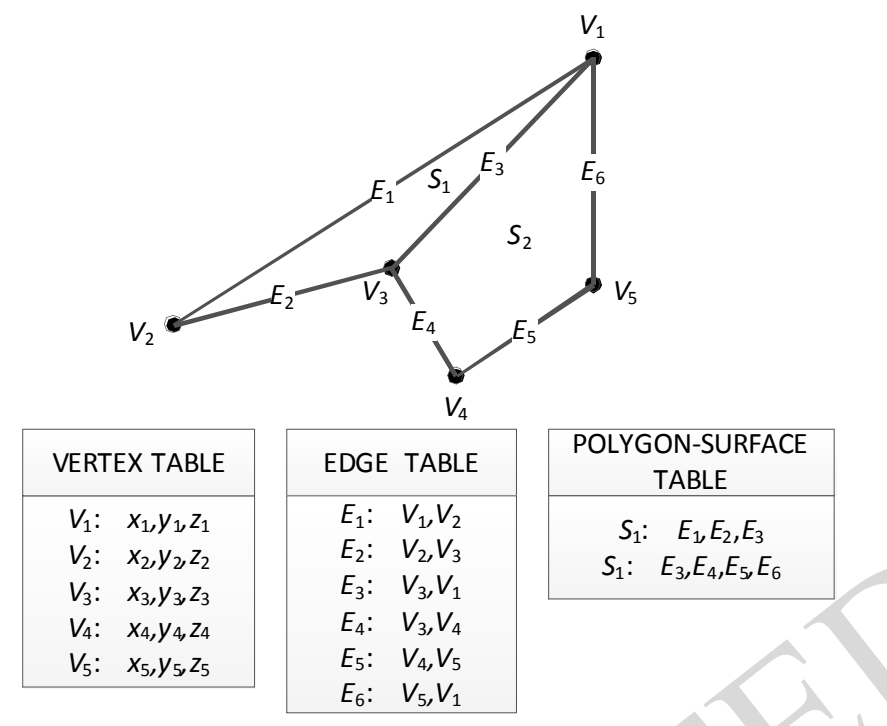

Fig. (1). Two adjacent polygon geometry.

Among them, a, B are respectively the pinhole camera projection plane two directions in Euclidean space unit vector, they can be mutually perpendicular, D is from the point of observation vector, pointing to the origin of the world coordinate system image by a, B can be composed of an observation matrix $P$.

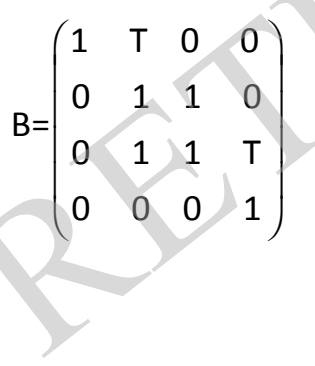

$B_{k}=\frac{1}{N}\left(f_{k}+f_{k-1}+\cdots f_{k-N-1}\right)$

Coordinate with $\mathrm{X}$ in Euclidean space is denoted as Eucll.dx (), then:

$v(k)=[0, u 1(k), 0, u 2(k)]^{T}$

$\mathrm{P}(k)=E\left[w(k) w^{T}(k)\right]=\left(\begin{array}{llll}0 & 0 & 0 & 0 \\ 0 & 0 & \sigma_{1}^{2} & 0 \\ 0 & 0 & 0 & 0 \\ 0 & 0 & 0 & \sigma_{2}^{2}\end{array}\right)$

$\mathrm{V}(k)=E\left[v(k) v^{T}(k)\right]=\left(\begin{array}{cc}\sigma_{x}^{2} & 0 \\ 0 & \sigma_{y}^{2}\end{array}\right)$

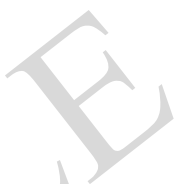

This is the ultimate expression of 3DWapr algorithm.

\subsection{The Basic Principle of 2D Texture Mapping}

The essence of $2 \mathrm{D}$ texture mapping is the function to the object surface texture mapping a given. Generally, a 2D texture defined in a planar area, it can be expressed with mathematical analytic function, can also be defined using a variety of discrete digital image. The texture mapping is generally divided into two steps: one is to determine the texture properties; two is the mapping to establish the relationship between the texture space and scenery space and scenery space and screen space. The texture properties of the scene surface mainly has several: one is the surface color, namely diffuse reflection coefficient of the surface; two is the specular reflection component, namely the specular reflection coefficient of the surface; three is the transparency; four is the surface normal vector, namely disturbance surface method always have bump surface; the five is the environment of diffuse and specular effect. The process of mapping texture in Fig. (2) is expressed as:

From the object space in a certain area of mapping $\mathrm{P}$ to texture space, i.e., determine the object space coordinates $\mathrm{x}$, $\mathrm{y}, \mathrm{z}$ the corresponding texture coordinates $(\mathrm{U}, \mathrm{V})$, which is actually the process of curved surface slice parametric. This process from a mathematical point of view to describe as:

$(u, v)=F(x, y, z)$
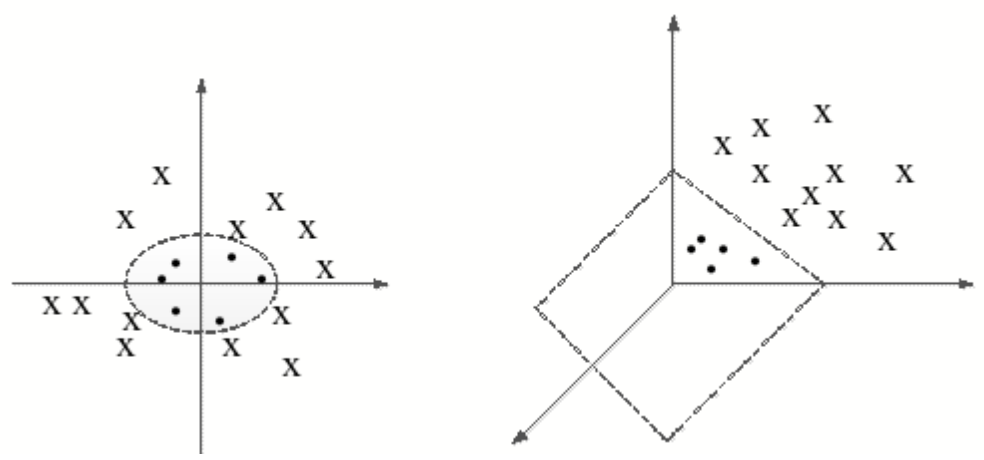

Fig. (2). The process of mapping texture. 


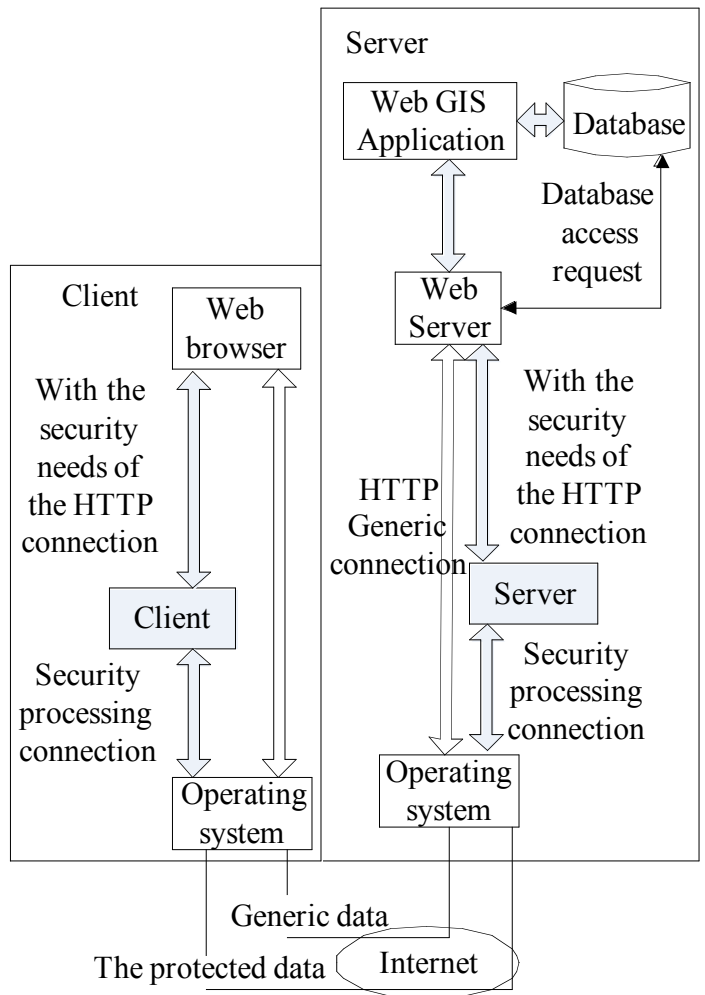

Fig. (3). The logic diagram of the concrete system.

For a simple two surface, texture mapping function can be expressed analytically, and for higher order parametric surface can not be good for parsing expression, generally requires the use of numerical solution technique to the discrete expression. Here is a simple example of two surface, a height of $\mathrm{H}$, parameter form radius $r$ of the cylindrical surface available below to expression:

$$
:\left\{\begin{array}{l}
x_{1}=\left(a_{1} \theta+e_{1}\right) \cos (\theta) \\
y_{1}=\left(a_{1} \theta+e_{1}\right) \sin (\theta)
\end{array}\right.
$$

$$
:\left\{\begin{array}{l}
x_{2}=\left(a_{2} \theta+e_{2}\right) \cos (\theta) \\
y_{2}=\left(a_{2} \theta+e_{2}\right) \sin (\theta)
\end{array}\right.
$$

\subsection{The Overall Structure of the GIS Data Transmission Security Platform}

Security agent middleware mainly consists of two parts: client security proxy and server security agent. For the security of client agent, it can be divided into two parts, namely the HTTP protocol agent part and security communication part. Its main role is as follows. The logic diagram of the concrete system is shown in Fig. (3).

How to make some of the more cluttered digital data collated into accord with the process data in GIS format, as well as other topology processing, is the decision point, line, surface topology and add a certain point, line, surface, or a kind of topological relations into another topological relationship, or add some topology process relationship (below use the " $\varepsilon$ " said tiny positive). (4).

Online left (right), line extension line was shown in Fig.

\section{RESULTS AND DISCUSSION}

\subsection{Physical Structure Design}

Considering the computer hardware equipment constraints and other reasons, the model file model library considering storage, file system, of course, can also be considered by the Oracle database management system as the background support. A model of attribute data by Access relational database management system for direct management, as shown in Fig. (5).

Table 1 shows the traffic planning spatial database structure.

The various elements of the entity of urban traffic, through appropriate screening, expressed by graph and digi-
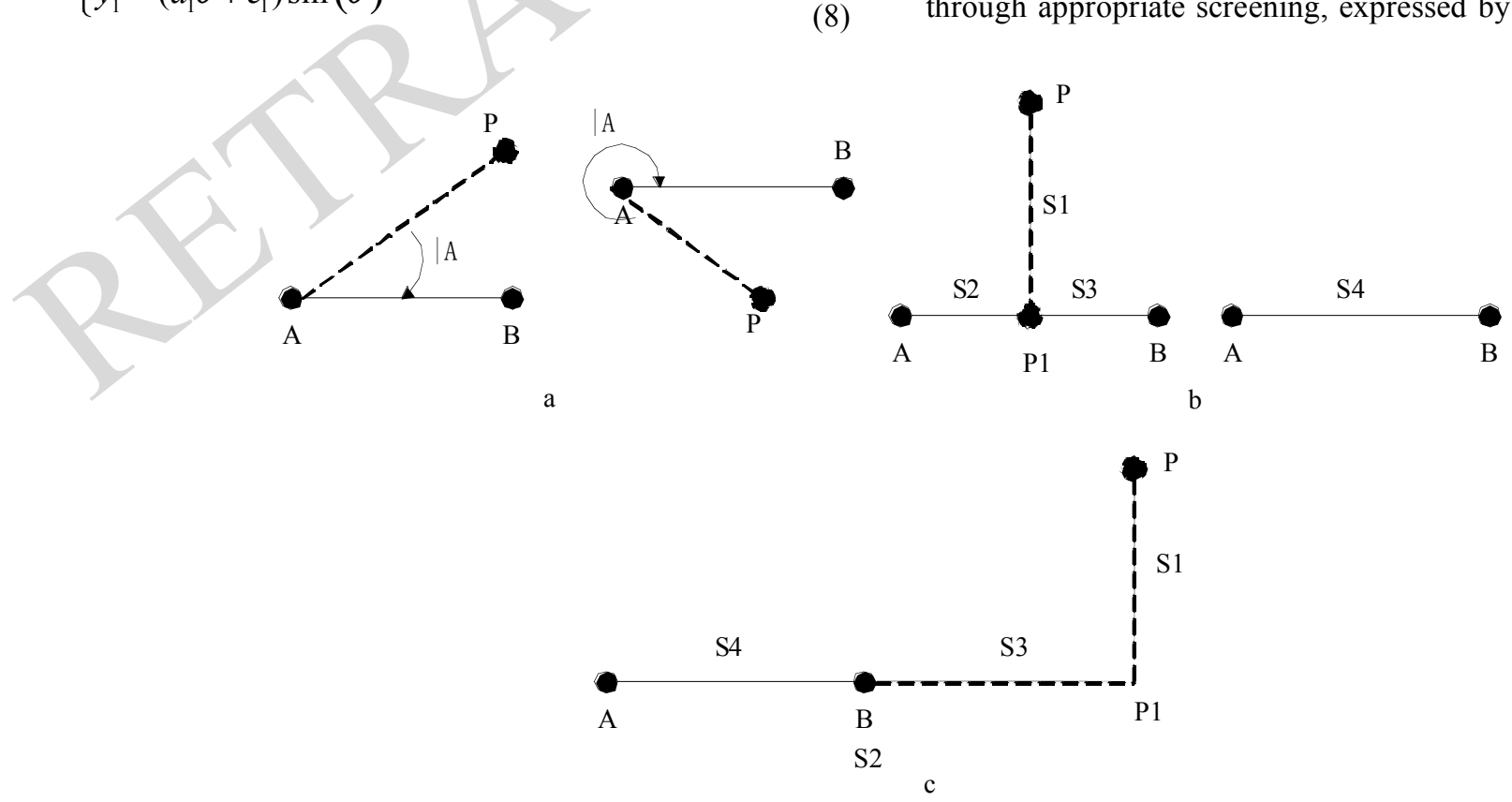

Fig. (4). Online left (right), line extension line. 


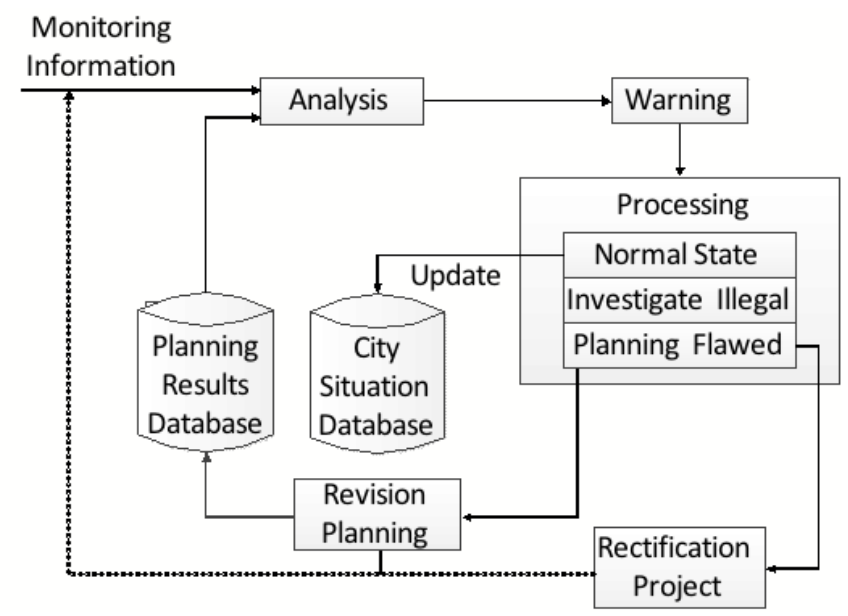

Fig. (5). A model of attribute data by access relational database management system for direct management.

Table 1. City traffic planning spatial database structure design table.

\begin{tabular}{|c|c|c|}
\hline Layer Name & Abstract Layer & Main Attribute \\
\hline \hline Intersection & Point & Intersection name, Intersecting road, Control method \\
\hline Main road & Line & Road name, road grade, length, red line width \\
\hline Urban land & Plane & Land properties and area \\
\hline Traffic area & Plane & Traffic area code, population, area \\
\hline main group & Point & Group name, Group properties \\
\hline
\end{tabular}

tal form, namely GIS entity of urban traffic is abstracted to a different level, where each layer of storage characteristics of the same or similar geographical phenomena. In transportation planning, traffic network will have a linear feature abstraction in sections for line; urban and road intersection traffic node, point to describe; administrative division, traffic area, land etc. can be abstracted as a plane or polygon. GIS uses the concept of layers to management and storage, transportation planning information analysis of different time and different attributes, and then put these layer stacking up, to realize the visualization of the study area of traffic information, in order to increase the scientific planning. GIS "layer" concept was shown in Fig. (6).

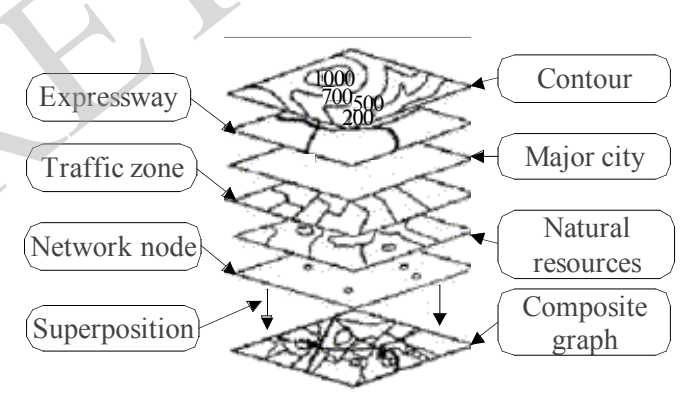

Fig. (6). GIS "layer" concept.

The main function of the management information system of city traffic planning is for the convenience of city traffic management, the promotion of city traffic layout and benign circulation, provides a set of application system more practical for planning department and the corresponding transportation management. Therefore, from the user point of view, to the daily business management needs as the guidance, strengthening of the characteristics, city traffic basic geographic traffic planning resources and city traffic planning function zoning of the data query and analysis functions, browsing system function frame was shown in Fig. (7).

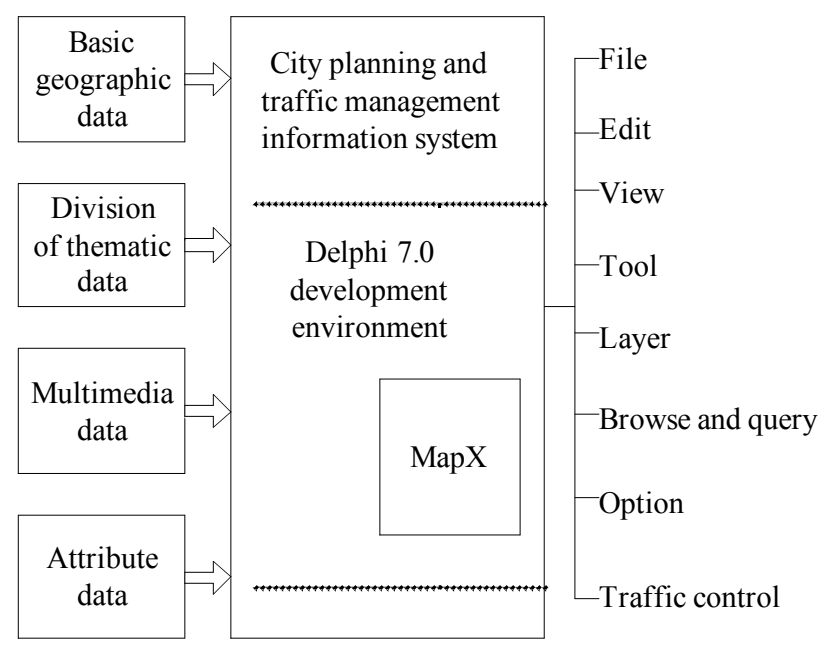

Fig. (7). Analysis functions, browsing system function frame.

\section{CONCLUSION}

The 3D City Modeling Based on city planning is a new try of planning and design method, the experimental process, edit in the realization of 3D city model display, flight, browsing, and achieved good results. But also on the city model object attribute query, provides support for simple 
planning analysis, for the further implementation of the planning function based analysis and lays down the. This paper studies the theory and technology of city planning, analyzes the current city planning information system development in the existing problems, this paper briefly introduces the new situation of the Internet combined with GIS generated by the GIS, puts forward the design scheme based on Internet.

\section{CONFLICT OF INTEREST}

The authors confirm that this article content has no conflict of interest.

\section{ACKNOWLEDGEMENTS}

Declared none.

\section{REFERENCES}

[1] L. Rudin, P. Lions, and S. Osher, "Multiplicative denoising and deblurring: theory and algorithms," in Osher S and Paragios N, Edi- tors, Geometric Level Set Methods in Imaging, Vision and Graphics, Springer, pp. 103-119, 2003.

[2] L. Denis, F. Tupin, J. Darbon, and M. Sigelle, "SAR Image Regularization with Fast Approximate Discrete Minimization," IEEE Trans Image Process, vol. 18, no. 7, pp. 1588-600, 2009.

[3] J. Shi, and S. Osher, "A Nonlinear Inverse Scale Space Method for a Convex Multiplicative Noise Model," SIAM J. Imaging Sciences, vol. 1, no. 3, pp. 294-321, 2008.

[4] Y. Huang, L. Moisan, M.K.Ng, and T. Zeng, "Multiplicative Noise Removal via a Learned Dictionary," Image Processing, IEEE Transactions on, vol. 21, no. 11, pp. 4534-4543, 2012.

[5] D. Chen, and L. Cheng, "Spatially Adapted Total Variation Model to Remove Multiplicative Noise," Image Processing, IEEE Transactions on, vol. 21, no. 4, pp. 1650-1662, 2012.

[6] A. Dang, H. Shi, and Q. Mao, "GIS and RS Application Study on Urban Dynamic Development," Geographic Information Sciences, vol. 8 , no. 2 , pp. $122 \sim 128,2002$.

[7] C. R. Council, "Review of capital city strategic planning systems," COAG Reform Council, Sydney, 2012.

[8] Fuzzy planning, "The role of actors in a fuzzy governance environment," Ashgate Publishing, Ltd., 2012.

[9] S. Larson, "Building Like Moses with Jacobs in Mind": Contemporary Planning in New York City," Temple University Press, 2013.

(C) Xiaoping et al.; Licensee Bentham Open.

This is an open access article licensed under the terms of the (https://creativecommons.org/licenses/by/4.0/legalcode), which permits unrestricted, noncommercial use, distribution and reproduction in any medium, provided the work is properly cited. 